\title{
LA POTESTAD DEL SERNAC PARA RECIBIR RECLAMOS Y PROMOVER ACUERDOS INDIVIDUALES LUEGO DE SER ELIMINADA POR EL TRIBUNAL CONSTITUCIONAL
}

\author{
THE POWER OF THE CHILEAN CONSUMER PROTECTION \\ AGENCY TO RECEIVE CLAIMS AND SUPPORT AGREEMENTS \\ BETWEEN CONSUMER AND SUPPLIER
}

PABLO SOTO DELGADO*

\section{RESUMEN}

La sentencia del Tribunal Constitucional que declaró inconstitucionales las normas del proyecto de ley que fortalecía al SERNAC, referidas a la denuncia, mediación y conciliación individual dejó a este órgano sin una normativa expresa para tramitar reclamos y promover acuerdos entre consumidor y proveedor. Sobre la base de argumentos constitucionales, administrativos y regulatorios, el artículo sostiene que, a pesar de lo anterior, es posible que el servicio implemente, administrativamente, un mecanismo al efecto.

Palabras clave: SERNAC, potestades implícitas, Derecho del consumo, Derecho administrativo.

\footnotetext{
* Profesor de Derecho Administrativo. Investigador adjunto, Facultad de Derecho de la Universidad Diego Portales. Correo electrónico: pablo.soto@mail.udp.cl.

Artículo recibido el 4 de diciembre de 2018 y aceptado para su publicación el 20 de mayo de 2019.
} 


\section{ABSTRACT}

The Chilean Constitutional Court decided that part of the bill that would improve the National Consumer Protection Agency (SERNAC) was unconstitutional, leaving this public body without an explicit regulation to process individual claims and promote agreements between consumer and supplier. Based on constitutional, administrative and regulatory reasons, the article argues that, despite the foregoing, the agency has the power to implement a mechanism for that purpose.

Keywords: Chilean Consumer Protection Agency, inherent powers, Consumer Law, Administrative Law.

\section{OBJETIVO E ITINERARIO}

La sentencia del Tribunal Constitucional (TC) que impidió convertir en ley diversas potestades que el legislador intentó atribuir al Servicio Nacional del Consumidor (SERNAC) a través del proyecto de ley que pretendía fortalecer a ese órgano, ${ }^{1}$ declaró inconstitucional la nueva configuración de la mediación y conciliación individual, previa denuncia del consumidor. ${ }^{2}$ Esto aconteció junto con la derogación, en el mismo proyecto de ley, del anterior precepto que establecía la posibilidad que el consumidor reclamara ante el servicio, que debía comunicar el requerimiento al proveedor y promover un entendimiento voluntario entre ambas partes.

Considerando el impacto público que causó el que el SERNAC haya quedado desprovisto de una herramienta de muy frecuente utilización por parte de los consumidores, este texto tiene por objeto esclarecer si dicho servicio puede implementar administrativamente alguna modalidad de recepción de reclamos y promover un entendimiento voluntario individual, a pesar de la declaración de inconstitucionalidad del TC, y de la derogación que se produjo de tales atribuciones, esto es, no obstante la inexistencia de

\footnotetext{
1 Cámara de Diputados, Oficio No 13.600, 26 de octubre de 2017, proyecto de ley (totalmente tramitado) que modifica la ley $\mathrm{N}^{\circ} 19.496$, sobre Protección de los Derechos de los Consumidores, correspondiente al boletín $\mathrm{N}^{\circ}$ 9.369-03. En lo que sigue, las referencias a las normas declaradas inconstitucionales por el TC se rigen por la numeración de este documento.

2 Tribunal Constitucional, 18 de enero de 2018, Rol No 4012-17.
} 
una norma habilitante expresa al efecto. Esta indagación es especialmente pertinente a propósito del SERNAC, pues, como se verá, éste es un órgano al cual se ha reconocido una amplia capacidad para interpretar sus propias normas y ejercer potestades que no se encuentran explícitamente establecidos en ellas.

Para llevar a cabo el propósito precedente, el artículo identifica, en primer término, cómo las intervenciones del legislador y el TC produjeron que el SERNAC quedara sin habilitación normativa para recibir reclamos ni promover individualmente un entendimiento voluntario entre consumidor y proveedor. En segundo lugar, se da cuenta de las disposiciones que regulaban la materia en la Ley N ${ }^{\circ}$ 19.496, sobre Protección de los Derechos de los Consumidores (LPDC), así como las normas del proyecto de modificación que sustituían a las primeras. Enseguida, se exponen diversos criterios que servirán para el análisis posterior, consistentes en argumentos constitucionales y administrativos, especialmente provenientes de la jurisprudencia de la Contraloría General de la República (CGR) y el TC respecto al SERNAC, así como desde el derecho regulatorio. Luego, sobre la base de estos fundamentos, se presenta una respuesta a la interrogante aquí planteada. Finalmente, el texto resume las conclusiones.

\section{UN TRIBUNAL CONSTITUCIONAL A FAVOR DEL PROVEEDOR Y UNA MALA TÉCNICA LEGISLATIVA}

El TC consideró inconstitucionales distintas disposiciones del proyecto de ley que fortalecía al SERNAC. Entre las razones para tal juicio sobre las nuevas atribuciones -sancionatoria, normativa, requerir información a otros servicios públicos, y mediación individual- se sostuvo que el servicio estaría actuando como un verdadero juez (y parte) y que, en verdad, en esta clase de asuntos, en los que existen intereses particulares contrapuestos entre consumidor y proveedor, el Estado no puede actuar sino a través del Poder Judicial. $^{3}$ La preocupación del TC estuvo dirigida a resguardar los derechos de los proveedores, como expresamente lo señaló al aseverar que una regulación como la propuesta fallaba puesto que debió haber protegido los derechos de aquellos, a quienes estima como "el prójimo". ${ }^{4}$

\footnotetext{
3 Véase el desarrollo específico de esta argumentación del TC más abajo en la parte IV, sección 5.1.

4 Tribunal Constitucional, 18 de enero de 2018, cit. (n. 2), considerando 39 . En la comunidad académica nacional se produjeron opiniones críticas respecto a esta sentencia, por no ajustarse a la
} 
El TC evitó que la nueva ley ${ }^{5}$ contuviera normas que fijaban un procedimiento de denuncia, mediación, y conciliación individual (artículo $50 \mathrm{G}$ del proyecto), así como la regla que confería competencia al SERNAC en la materia (literal o) del artículo 58 inciso $2^{\circ}$ ). Ahora bien, en una situación ideal, a pesar de la declaración de inconstitucionalidad de estas nuevas atribuciones, la norma previa (el artículo 58 inciso $2^{\circ}$ letra f) de la LPDC) podría haberse mantenido vigente $y$, en consecuencia, subsistir la habilitación expresa para que el SERNAC reciba reclamos de los consumidores, los comunique a los proveedores y promueva un entendimiento voluntario entre ambos.

Sin embargo, también las normas anteriores terminaron derogadas, lo que se debió a una deficiente técnica legislativa de agrupación de normas en el proyecto. ${ }^{6}$ En efecto, el artículo $1^{\circ}$ numeral 52 del proyecto de ley ordenó sustituir ("Reemplázanse" pone el legislador) varios literales — de la a) a la g) — del artículo 58 inciso $2^{\circ}$ de la LPDC que, en su letra f) habilitaba al SERNAC para recibir reclamos de consumidores y comunicarlos al proveedor para que este voluntariamente proponga soluciones. Esto significa que, a causa de la sustitución ordenada por el legislador, se eliminó el antiguo artículo 58 inciso $2^{\circ}$ de la LPDC, quedando un artículo 58 inciso $2^{\circ}$ nuevo sin la letra f) anterior, que establecía la recepción de reclamos, su notificación y la promoción del entendimiento voluntario $\mathrm{y}$, por la declaración de inconstitucionalidad del TC, sin la potestad del SERNAC para recibir denuncias, mediar y conciliar individualmente.

Por cierto, no puede señalarse que haya sido intención del TC generar el problema, que no se produciría si el legislador hubiese empleado una técnica de sustitución que separaba cada una de las modificaciones a las disposiciones que establecían las nuevas atribuciones del servicio, aunque

práctica constitucional desarrollada previamente por el propio TC y subvertir la relación de consumo, en la cual, quien está comparativamente en una peor situación es el consumidor, debiendo ser, por ello, el principal sujeto de preocupación para la protección estatal, según lo señalado por Soто, Pablo, "El giro conservador en torno a las sanciones administrativas por obra del Tribunal Constitucional en Chile: transformando a la Administración en juez para desproteger el interés público", Revista de la Facultad de Derecho de la Universidad de la República (Uruguay), 2018, № 45, p. 404.

${ }^{5}$ Ley N ${ }^{0} 21.081,2018$.

6 Calificada como una agrupación por "fardos" según Barrientos, Francisca; Soto, Pablo, "La teleserie legislativa sobre el texto de la ley de reforma del SERNAC: algunas propuestas", https:// www.elmostrador.cl/noticias/opinion/2018/04/02/la-teleserie-legislativa-sobre-el-texto-de-la-ley-dereforma-del-sernac-algunas-propuestas/, 3 de diciembre de 2018. 
el saldo es que el SERNAC, en este aspecto, quedó en peor condición, ${ }^{7}$ a pesar que el legislador en ningún caso quiso eliminar la capacidad de recibir reclamos, comunicarlos, y promover un entendimiento individual entre proveedor y consumidor, sino solo remplazarla. Como consecuencia, los consumidores, formalmente, carecen de un mecanismo para acudir ante el servicio frente a lo que consideran una vulneración de sus derechos por parte de los proveedores, por falta de una expresa provisión legal.

\section{LA REGULACIÓN DEROGADA Y LA QUE SE DECLARÓ INCONSTITUCIONAL}

En esta parte se explica la regulación de los reclamos, su comunicación y la promoción del entendimiento individual entre proveedor y consumidor antes del proyecto de reforma a la LPDC, así como la normativa que en este último el legislador intentó introducir, destacándose sus diferencias.

\section{El derogado artículo 58 inciso $2^{\circ}$ letra f) de la Ley $N^{\circ} 19.496$}

El sustituido artículo 58 inciso $2^{\circ}$ letra f) de la LPDC se encontraba, desde un punto de vista sistemático, ubicado en la disposición cuyo inciso $1^{\mathrm{o}}$ define la función general del servicio, ${ }^{8}$ consistente en "velar por el cumplimiento de las disposiciones de la presente ley y demás normas que digan relación con el consumidor, difundir los derechos y deberes del consumidor y realizar acciones de información y educación del consumidor." En el siguiente inciso se establece — pues, sigue vigente - un encabezado que no clausura las funciones específicas del órgano, desarrolladas bajo los literales a) a ñ) ahora derogados. Esta falta de taxatividad obedece a que tales atribuciones "corresponderán especialmente" al SERNAC, es decir, no son las únicas tareas que puede desempeñar el servicio y a que, como luego se verá, los incisos $1^{\circ}$ y el encabezado del inciso $2^{\circ}$ del artículo 58 han sido interpretados teleológicamente. ${ }^{9}$ Entre estas facultades especificadas, aunque no taxativas, se hallaba el contenido en la letra f) del artículo 58

\footnotetext{
7 Lo cual aparece dicho por Soto, cit. (n. 4), p. 405.

8 Tratada como una "función genérica y cláusula general de competencia" del SERNAC, en IsLER, Erika, “Artículo 58”, en: De la Maza, Íñigo y Pizarro, Carlos (Dirs.); Barrientos, Francisca (Coord.), La protección de los derechos de los consumidores. Comentarios a la Ley de protección a los derechos de los consumidores, Legal Publishing-Thomson Reuters, Santiago, 2013, p. 1.131.

9 Véase, más abajo, la Parte IV, sección 2.
} 
inciso $2^{\circ}$ en comento, según la cual, correspondía al órgano:

"Recibir reclamos de consumidores que consideren lesionados sus derechos y dar a conocer al proveedor respectivo el motivo de inconformidad a fin de que voluntariamente pueda concurrir y proponer las alternativas de solución que estime convenientes. Sobre la base de la respuesta del proveedor reclamado, el Servicio Nacional del Consumidor promoverá un entendimiento voluntario entre las partes. El documento en que dicho acuerdo se haga constar tendrá carácter de transacción extrajudicial y extinguirá, una vez cumplidas sus estipulaciones, la acción del reclamante para perseguir la responsabilidad contravencional del proveedor(.)"

Esta disposición obligaba al SERNAC a tres tareas: (i) recibir reclamos de los consumidores; (ii) comunicarlos al proveedor; y (iii) promover un entendimiento voluntario entre ambos (instancia conocida también como "mediación individual"). ${ }^{10}$ La norma antes transcrita fue fijada a la letra f) del inciso $2^{\circ}$ del artículo 58 de la LPDC mediante la Ley $\mathrm{N}^{\mathrm{o}} 19.955,{ }^{11}$ de 2004; previo a esto, se encontraba, conforme al texto original de la Ley $\mathrm{N}^{\circ} 19.496$, de 1997, en su artículo 50, bajo los siguientes términos:

“(...) los consumidores que consideren lesionados sus derechos puedan reclamar de ello ante el Servicio Nacional del Consumidor, quien dará a conocer al proveedor respectivo el motivo de inconformidad a fin de que voluntariamente pueda concurrir y proponer las alternativas de solución que estime convenientes. Sobre la base de la respuesta del proveedor reclamado, el Servicio Nacional del Consumidor promoverá un entendimiento voluntario entre las partes. El documento en que dicho acuerdo se haga constar tendrá carácter de transacción extrajudicial y extinguirá, una vez cumplidas sus estipulaciones, la acción del reclamante para perseguir la responsabilidad contravencional del proveedor."

\footnotetext{
${ }^{10}$ Como se explica en IsLeR, cit. (n. 8), p. 1.140, señalando la impropiedad técnica de tal denominación, cuestión confirmada por BarRientos, Francisca; Fuentes, Claudio; Vargas, Juan Enrique, "“Mediaciones individuales' y 'mediaciones colectivas' que realiza el Servicio Nacional del Consumidor", en: VÁsQuEz, María Fernanda (Dir.), Mecanismos alternativos de solución de conflictos. Estado actual, problemas existentes y propuesta de soluciones, Thomson Reuters, Santiago, 2018, pp. 132-135.

${ }^{11}$ Ley No 19.955, 2004.
} 
2. La denuncia, mediación y conciliación individual en el proyecto de fortalecimiento del SERNAC

Por su parte, en el proyecto de reforma a la LPDC, la denuncia, mediación y conciliación individual se bifurcaba en dos normas, ambas declaradas inconstitucionales por el TC. Mientras la primera de ellas (artículo 58 letra o) otorgaba al servicio competencia al respecto, la segunda disposición —el artículo $50 \mathrm{G}$, que contenía catorce incisosdesarrollaba el procedimiento y efectos jurídicos de la nueva regulación, que esquemáticamente operaba como lo explica la siguiente tabla.

\begin{tabular}{|l|l|}
\hline DENOMINACIÓN & DESCRIPCIÓN \\
\hline $\begin{array}{l}\text { Requisitos de denuncia } \\
\text { ante el SERNAC }\end{array}$ & $\begin{array}{l}\text { Por escrito, incluyendo vía electrónica; señalando lugar, fecha } \\
\text { de presentación, individualización del denunciante; suscripción: } \\
\text { personal, mandatario o representante. Denuncia debe contener: } \\
\text { descripción de hechos concretos constitutivos de la infracción, } \\
\text { precisando lugar y fecha de su comisión e identificar al proveedor } \\
\text { a lo menos por su denominación en el comercio. }\end{array}$ \\
\hline $\begin{array}{l}\text { Comunicación al } \\
\text { proveedor y propuestas } \\
\text { de solución }\end{array}$ & $\begin{array}{l}\text { Denuncia se comunica al proveedor para que éste obligatoriamente } \\
\text { proponga alternativas concretas de solución o corrección al hecho } \\
\text { denunciado; respuesta por escrito, dentro de siete días hábiles. }\end{array}$ \\
\hline $\begin{array}{l}\text { Aceptación de la } \\
\text { propuesta, transacción } \\
\text { extrajudicial, extinción } \\
\text { de acciones y mérito } \\
\text { ejecutivo del acuerdo } \\
\text { voluntario }\end{array}$ & $\begin{array}{l}\text { Si el denunciante acepta, se produce acuerdo voluntario (constar } \\
\text { por escrito, carácter de transacción extrajudicial, extinguiéndose } \\
\text { las acciones civiles y contravencionales una vez cumplidas } \\
\text { las estipulaciones). Requiere certificación por el funcionario } \\
\text { encargado de tramitar la denuncia. El acta de la transacción, } \\
\text { certificada, tendrá mérito ejecutivo. }\end{array}$ \\
\hline $\begin{array}{l}\text { Rechazo de la propuesta, } \\
\text { conciliación obligatoria } \\
\text { y renuncia a conciliación }\end{array}$ & $\begin{array}{l}\text { Si el consumidor no acepta la propuesta del proveedor, o si éste no } \\
\text { propusiere alternativas de solución o corrección, hay una audiencia } \\
\text { obligatoria de conciliación. La audiencia de conciliación se cita } \\
\text { de inmediato, es breve y desformalizada; plazo no inferior a siete } \\
\text { días hábiles; citación por correo electrónico o carta certificada. El } \\
\text { consumidor siempre podrá renunciar a la audiencia ratificando su } \\
\text { denuncia. }\end{array}$ \\
\hline
\end{tabular}




\begin{tabular}{|l|l|}
\hline DENOMINACión & DEsCRIPCión \\
\hline $\begin{array}{l}\text { Características } \\
\text { de la audiencia } \\
\text { de conciliación y } \\
\text { comparecencia }\end{array}$ & $\begin{array}{l}\text { Las conciliaciones podrán ser no presenciales a través de } \\
\text { medios tecnológicos. A la audiencia deberán asistir consumidor } \\
\text { y proveedor, personalmente, o a través de terceros con poder } \\
\text { suficiente para transigir. En la audiencia, el funcionario a cargo } \\
\text { llamará a las partes a una conciliación para lo cual formulará } \\
\text { bases concretas de acuerdo, las que deberán ser respondidas por } \\
\text { las partes. }\end{array}$ \\
\hline $\begin{array}{l}\text { Acta de conciliación, } \\
\text { mérito ejecutivo y } \\
\text { extinción de acciones }\end{array}$ & $\begin{array}{l}\text { De lo obrado en la audiencia y de la eventual conciliación } \\
\text { alcanzada se levantará un acta por el funcionario a cargo de la } \\
\text { conciliación, que será suscrita por todos los comparecientes. } \\
\text { En caso de acuerdo, el acta deberá expresar las obligaciones } \\
\text { contraídas por el proveedor y la forma y plazo de cumplimiento } \\
\text { de las mismas. El acta de la conciliación, debidamente certificada, } \\
\text { tendrá mérito ejecutivo. Una vez cumplidas las estipulaciones del } \\
\text { acuerdo se extinguirán las acciones del denunciante para perseguir } \\
\text { la responsabilidad contravencional y civil del proveedor. }\end{array}$ \\
\hline $\begin{array}{l}\text { Sanción por no } \\
\text { responder o incumplir } \\
\text { estipulaciones de } \\
\text { conciliación }\end{array}$ & $\begin{array}{l}\text { Si el proveedor no da respuesta dentro de plazo, incumple la } \\
\text { solución o corrección propuesta en su respuesta, o incumple las } \\
\text { obligaciones contraídas en la conciliación, será sancionado con } \\
\text { arreglo a lo dispuesto en el artículo 24 de esta ley. }\end{array}$ \\
\hline $\begin{array}{l}\text { Conciliación fallida y } \\
\text { requisitos para iniciación } \\
\text { de procedimiento } \\
\text { administrativo } \\
\text { sancionatorio }\end{array}$ & $\begin{array}{l}\text { El acta que declara fallida la conciliación o la ratificación de la } \\
\text { denuncia originará un procedimiento sancionatorio si la denuncia } \\
\text { tiene seriedad y los hechos pueden constituir infracción de la } \\
\text { legislación del consumo. El servicio puede solicitar información } \\
\text { adicional y disponer acciones de fiscalización sobre el proveedor. }\end{array}$ \\
\hline $\begin{array}{l}\text { Expediente } \\
\text { Todo el procedimiento deberá constar en un expediente, escrito o } \\
\text { electrónico. }\end{array}$ \\
\hline
\end{tabular}

\section{Comentario sobre ambas regulaciones}

Una primera cuestión que debe destacarse es que según el nuevo artículo $50 \mathrm{G}$, la denuncia daba lugar a la conciliación y mediación, instancias que, fracasadas, y habiendo mérito para ello, habrían permitido al SERNAC proseguir la tramitación administrativa sancionatoria. Es decir, la denuncia era uno de los modos de iniciación del procedimiento sancionador. ${ }^{12}$ En

\footnotetext{
${ }^{12}$ Los incisos $1^{\circ}$ y $2^{\circ}$ del artículo $50 \mathrm{G}$ disponían, en lo pertinente: "El procedimiento administrativo sancionatorio podrá iniciarse de oficio o por denuncia. (...) Se iniciará por denuncia cuando, interpuesta
} 
rigor, la evaluación de la seriedad de la denuncia para que el SERNAC iniciara el procedimiento sancionador quedaba en suspenso hasta no agotar la mediación y conciliación. Como segundo punto, resulta claro que la nueva institucionalidad era más detallada y estatuía los pasos, características y requisitos de la denuncia, mediación y conciliación, estableciendo distintos cursos de acción administrativos según el comportamiento de las partes (aceptar o no la propuesta, conciliar o no, etc.), lo cual no se contenía en el antiguo artículo 58 inciso $2^{\circ}$ letra f) de la LPDC, cuya falta de densidad normativa posibilitó que el SERNAC regulara tal facultad a través de una resolución del jefe del servicio. ${ }^{13}$

En tercer lugar, el artículo $50 \mathrm{G}$ del proyecto pretendía agregar una conciliación obligatoria, con un deber de las partes de responder las bases de arreglo que el servicio propusiera, a diferencia del artículo 58 inciso $2^{\circ}$ letra f) derogado, que sólo contenía el deber del SERNAC de promover un "entendimiento voluntario". En cuarto término, el artículo 50 G confería mérito ejecutivo al acta certificada en que constara el acuerdo de la mediación o de la conciliación, cuestión que el artículo 58 inciso $2^{\circ}$ letra f) antiguo no contenía; y en ambas normas el acuerdo entre proveedor y consumidor se denominaba "transacción extrajudicial".

Enseguida, los artículos $50 \mathrm{G}$ y 58 inciso $2^{\circ}$ letra f) establecían que se extinguían las acciones en caso que se obtuviera un acuerdo entre proveedor y consumidor. En el primer caso, esto operaba respecto a las acciones contravencionales y civiles una vez cumplidas sus estipulaciones, lo que también acontecía en la conciliación; por su parte, por la segunda norma sólo se extinguían las acciones contravencionales. Finalmente, se incorporaba, a través del artículo $50 \mathrm{G}$, una multa para el proveedor que (i) no propusiera soluciones dentro del plazo de siete días; (ii) incumpliera la solución o corrección que propone; e (iii) incumpliera las obligaciones contraídas en la conciliación. En virtud de esta sanción, se confirmaba la obligatoriedad de la propuesta del proveedor en la instancia individual de solución de conflicto luego de la denuncia del consumidor. Esta es una diferencia sustancial con la norma que se derogó por el legislador (el artículo 58 inciso $2^{\circ}$ letra f), según el cual, las propuestas de solución del proveedor eran voluntarias.

ésta en los términos señalados en el inciso siguiente, una vez que hayan fracasado las instancias de mediación y conciliación señaladas en este artículo, el Servicio estimare que existe mérito para ello (...)."

${ }^{13}$ Resolución Exenta No 420, de 8 de abril de 2016, denominada “Aprueba procedimiento de gestión de reclamos del Servicio Nacional del Consumidor". 


\section{CINCO CRITERIOS PARA EL ANÁLISIS}

En esta parte se explicitan los fundamentos que servirán para analizar, en la sección siguiente, la cuestión planteada en este texto.

\section{1.- Potestades implícitas}

Para la literatura administrativista española, no sólo la expresa atribución de potestades a un órgano administrativo es la única fuente para la actuación de la Administración del Estado, puesto que, junto a aquella explicitación típica, coexisten unos poderes inherentes o implícitos, cuyo objetivo es dar coherencia racional al sistema legal por vía interpretativa. ${ }^{14}$ Estas potestades no requieren constar manifiestamente en alguna disposición, sino que pueden inferirse a través de una interpretación finalista de las normas: cuando "una norma diseña un marco de regulación que ha de suponerse coherente y completo, ha de concluirse que atribuye todas las potestades necesarias -y solo ellas- para que la finalidad reguladora pueda cumplirse enteramente". ${ }^{15}$

En Chile, la doctrina también se ha pronunciado en torno a esta clase de potestades implícitas cuyo ejercicio compete a la Administración del Estado. Es así como, en las postrimerías de la década de los años setenta del siglo $\mathrm{XX}$, se postulaba el apoderamiento implícito o inherente como una forma de atribución de potestades administrativas, vinculada a otras normas del ordenamiento jurídico distintas a la ley (costumbres o principios generales del Derecho), así como a una interpretación finalista de las disposiciones legales, especialmente, en el ámbito de la intervención administrativa en materias económicas. ${ }^{16}$ Más recientemente, se ha sostenido que tales potestades son parte del principio de legalidad, aunque no puede, a través de ellas, desconocerse o excederse la competencia del respectivo órgano. ${ }^{17}$

\footnotetext{
${ }^{14}$ García de Enterría, Eduardo; Fernández, Tomás-Ramón, Curso de Derecho administrativo, CivitasThomson Reuters, Navarra, 2011, $15^{\text {a }}$ edición, tomo I, pp. 472 y 473.

15 Santamaría, Juan, Principios de Derecho administrativo general, Iustel, Madrid, 2004, tomo I, p. 426. En el mismo sentido, para García de EnTERría; Fernández, cit. (n. 14), p. 473, los poderes implícitos deben deducirse de otros poderes expresos.

${ }^{16}$ Oelckers, Osvaldo, "El principio de legalidad como supuesto de la potestad administrativa", Revista de Derecho Pontificia Universidad Católica de Valparaíso, 1977, № 1, pp. 133-135.

${ }^{17}$ Cordero Vega, Luis, Lecciones de Derecho administrativo, Thomson Reuters, Santiago, 2015, $2^{\mathrm{a}}$ edición corregida, p. 82.
} 
Estos poderes inherentes requieren:

"(a) la existencia de una facultad expresa en relación a un procedimiento administrativo que por sí sola sea imposible de ser ejercida; (b) que entre la facultad expresa y la implícita haya una relación de medio fin; (c) que la potestad implícita sea una consecuencia obvia y natural del núcleo esencial de la potestad asignada por la ley al órgano que instruye el procedimiento, y que en consecuencia no se encuentra depositada en o ejercida por otra autoridad administrativa". ${ }^{18}$

De esta propuesta, puede desprenderse que, mientras el primer criterio formula la relación de dependencia de la potestad implícita con la potestad expresamente fijada en la ley, el segundo supone que el poder inherente debe ser necesario para satisfacer la potestad expresa. Finalmente, el tercero muestra una vinculación al ámbito de competencia fijado para el respectivo órgano que detenta la potestad implícita y la explícita.

2. Los precedentes en la Contraloría sobre el SERNAC: un órgano con potestades implícitas

En lo que concierne a la actividad desplegada por el SERNAC, la doctrina de las potestades inherentes o implícitas ha sido traspasada a la práctica en distintos dictámenes de la Contraloría General de la República, en virtud de los cuales, mediante un ejercicio interpretativo, se ha considerado que ciertas atribuciones, a pesar de no encontrarse expresamente establecidas en la LPDC, se apegan a derecho y forman parte de las atribuciones del servicio.

Como cuestión primordial, la CGR ha sostenido que la protección de los intereses de los consumidores es un propósito público. En efecto, de conformidad a diversas normas de la LPDC, sostiene el órgano de control que el SERNAC ha sido creado por el legislador para el resguardo de los intereses de los consumidores. Por ello, es posible "inferir que defender los intereses de los consumidores constituye un fin propio del Estado, que se efectúa por medio del Servicio Nacional del Consumidor". ${ }^{19}$

\footnotetext{
${ }^{18}$ Cordero Vega, cit, (n. 17), p. 82.

${ }^{19}$ Contraloría General de la República, dictamen $\mathrm{N}^{\circ}$ 23.404, 26 de junio de 2000. Es una función propiamente estatal al punto que no es posible externalizarla, como consta en Contraloría General de la República, dictamen $\mathrm{N}^{\circ} 19.343,25$ de abril de 2005, conforme al cual, la CGR se abstuvo de tomar razón de la resolución del SERNAC que aprobaba las bases de licitación para contratar un servicio de atención
} 
La CGR ha admitido la fiscalización del SERNAC a Correos de Chile, en el entendido que las facultades fiscalizadoras han de leerse con arreglo a la función general de "velar" por el cumplimiento de las disposiciones legales y reglamentarias que se relacionaren con la protección de los derechos de los consumidores. Al efecto, se sostuvo que "(el artículo $58 \mathrm{~g}$ ) antes de su modificación por la Ley $\mathrm{N}^{\circ} 21.081$ ) no limita a la ley $\mathrm{N}^{\circ} 19.496$ la función del Servicio de velar por el cumplimiento de las disposiciones que digan relación con el consumidor, sino que la extiende también a las leyes especiales." ${ }^{20}$ Esta función de velar por las disposiciones legales y reglamentarias relacionadas con el resguardo de los derechos de los consumidores ha resultado especialmente crítica en dos dictámenes. En el primero de ellos, un grupo de parlamentarios solicitó que la CGR se pronunciara acerca de dos actuaciones del SERNAC, a saber: (i) la emisión de informes jurídicos respecto al cobro por el uso de estacionamientos en centros comerciales; y (ii) la constitución, sobre el mismo asunto, de una "mesa técnica", junto con el Ministerio de Transportes y Telecomunicaciones, el Ministerio de Vivienda y Urbanismo, el Ministerio de Economía, Fomento y Turismo, y los centros comerciales. Al efecto, la CGR concluyó, luego de explicar la cualidad de entidad descentralizada del servicio, que a éste le corresponde:

“...'velar por el cumplimiento de las disposiciones de la presente ley y demás normas que digan relación con el consumidor, difundir los derechos y deberes del consumidor y realizar acciones de información y educación del consumidor'. (...) Concordante con ello, el inciso segundo del precitado artículo 58, en su letra g), le asigna la función de velar por el cumplimiento de las disposiciones legales y reglamentarias relativas a la protección de los derechos de los consumidores y hacerse

telefónica dirigido a los consumidores. Afirma el referido pronunciamiento: "Como es dable advertir, la tarea asignada a los operadores telefónicos respectivos implica el ejercicio parcial de funciones que el artículo 58 de Ley N 19.496, sobre Protección de los Derechos de los Consumidores, encomienda precisamente a esa repartición estatal -relativas a velar por el cumplimiento de las disposiciones de esa ley y demás normas que digan relación con el consumidor, difundir los derechos y deberes del consumidor y realizar acciones de información y educación del consumidor-, las cuales deben por tanto ser ejercidas directamente por la misma y no pueden ser traspasadas a terceras entidades, máxime en cuanto las aludidas acciones no pueden considerarse como de mero apoyo o complemento de las labores propias del Servicio Público de que se trata, puesto que los ya mencionados operadores tomarán decisiones con la finalidad de clasificar la naturaleza de los hechos descritos por los administrados, e informarán a los mismos acerca de las soluciones previstas a su respecto por el ordenamiento jurídico, o bien derivarán la consulta, en base al juicio que tales particulares se han formado sobre el asunto, a otra oficina del Servicio o a otra entidad."

${ }^{20}$ Contraloría General de la República, dictamen N 68.467, 31 de octubre de 2012. 
parte en aquellas causas que comprometan los intereses generales de estos. (...) Ahora bien, de lo expuesto resulta que respecto de los consumidores el Estado, a través del SERNAC, debe velar por el acatamiento de las normas concernientes a ellos y a la protección de sus derechos, así como difundir sus derechos y deberes y realizar acciones para informar y educar a los mismos. (...) Luego, siendo un servicio público, ese organismo se encuentra en el imperativo de observar los principios de eficiencia y eficacia, y de cumplir sus cometidos coordinadamente, como asimismo, de propender a la unidad de acción, evitando la duplicación de funciones, en virtud de lo previsto en los artículos $1^{\circ}, 3^{\circ}$ y $5^{\circ}$ de la ley $\mathrm{N}^{\circ} 18.575$, Orgánica Constitucional de Bases Generales de la Administración del Estado. (...) En ese contexto normativo, esta Sede de Control no observa irregularidad en la circunstancia de que el SERNAC hubiere emitido, a través de informes jurídicos, su parecer en la materia a que se alude en la presentación que se atiende, y participado, junto con las individualizadas secretarías de Estado y particulares interesados, en una instancia técnica de análisis de la problemática vinculada al cobro de los estacionamientos, toda vez que ello se enmarca dentro de las funciones que la preceptiva en comento le ha encomendado, y en los principios antes reseñados". ${ }^{21}$

El segundo dictamen de alta importancia sobre este aspecto se refirió a la potestad del SERNAC para mediar colectivamente. En este caso, la Cámara de Comercio de Santiago A.G. solicitó a la CGR pronunciarse acerca de tal procedimiento, pues, a su juicio, el servicio carece de prerrogativas al efecto. En opinión del Contralor General de la República, son varias las disposiciones útiles para resolver el punto, a saber: (a) el artículo 57 (que crea el servicio como entidad descentralizada); (b) el artículo 58 inciso $1^{\circ}$ de la LPDC (que establece la función de velar por las disposiciones de la ley y otras que se relacionen con la protección de los derechos del consumidor); (c) el literal f) del artículo 58 (que admitía antes de la reforma por la Ley $\mathrm{N}^{\mathrm{o}} 21.081$ la recepción de reclamos y mediación individual voluntaria); (d) el artículo 51 de la LPDC (que, antes de la Ley No 21.081 establecía la potestad para que el servicio demandara con el objeto de proteger el interés colectivo o difuso de los consumidores). ${ }^{22}$

\footnotetext{
${ }^{21}$ Contraloría General de la República, dictamen No 43.644, 9 de julio de 2013.

${ }^{22}$ Contraloría General de la República, dictamen N 94.206, 4 de diciembre de 2014.
} 
Según la CGR, el encargo del SERNAC es "velar por el cumplimiento de las disposiciones de (la LPDC) y de las demás que se relacionen con el consumidor, de difundir sus derechos y deberes y de realizar acciones de información y educación del mismo". ${ }^{23}$ Por otro lado:

"teniendo en cuenta los preceptos citados; que es función del SERNAC velar por el cumplimiento de la normativa sobre protección de los derechos de los consumidores (la que incluye el resguardo del interés colectivo o difuso de los mismos luego de las modificaciones introducidas por la Ley $\mathrm{N}^{\circ}$ 19.955); los principios de eficiencia y eficacia que rigen el actuar de los órganos de la Administración del Estado, según los artículos $3^{\circ}$ y $5^{\circ}$ rigen el actuar de los órganos de la Administración del Estado, según los artículos $3^{\circ}$ y $5^{\circ}$ de la Ley $\mathrm{N}^{\circ} 18.575$, y lo manifestado en el dictamen $\mathrm{N}^{\circ} 71.055$, de 2013, de esta Institución Contralora, se concluye que esa repartición pública está facultada para, detectado un conflicto susceptible de afectar ese tipo de intereses, instar, a través de una mediación, a que aquél sea solucionado conjuntamente por los proveedores involucrados y los consumidores reclamantes".

Lo relevante de la revisión de la jurisprudencia de la CGR se halla en que, en lo que respecta a las materias de estos últimos dos dictámenes, la emisión de informes jurídicos, la incorporación a una mesa técnica, así como la mediación colectiva no se encontraban expresamente establecidas en las disposiciones orgánicas del servicio, conforme a la LPDC. ${ }^{24}$

Como se aprecia, la CGR otorga cobertura legal a tales actuaciones luego de analizar que el ordenamiento concede otras potestades al órgano, distintas a aquellas por las cuales se le consulta, y agrega en su argumentación los principios generales de eficiencia y eficacia contenidos en la Ley Orgánica Constitucional de Bases Generales de la Administración del Estado. Aunque los dictámenes no explican de qué modo se desprenden de las disposiciones que citan la legalidad de tales acciones, la conclusión es que los pronunciamientos de la entidad de control no hacen más que considerar como inherentes las atribuciones del SERNAC cuya legalidad resuelve. Esto adquiere especial sentido cuando, según los primeros pronunciamientos

\footnotetext{
${ }^{23}$ Contraloría General de la República, dictamen N 94.206, cit. (n. 22).

${ }^{24}$ Luego de la publicación de la Ley No 21.081, 2018, el procedimiento voluntario de solución de conflictos supraindividuales ha quedado regulado en los artículos 54 H y ss. de la Ley No 19.496, 1997.
} 
explicados, la CGR ya había dicho que la protección de los consumidores es una finalidad del Estado - es decir, normativamente es un dispositivo teleológico que otorga cobertura a un amplio rango de actuación- que, como función del SERNAC, no debe ser entendida de modo restringido. ${ }^{25}$

\section{Cumplimiento regulatorio y necesidad de obtener información}

Existen órganos de la Administración del Estado que se encuentran obligados a hacer que los administrados cumplan la regulación sobre la cual tienen competencia. Es lo que comúnmente acontece con las superintendencias en Chile, que han sido dotadas para ello de diversas facultades (normativas, fiscalizadoras, sancionadoras). De acuerdo con el derecho regulatorio, como todo ejercicio de poderes públicos, el cumplimiento normativo requiere, usualmente, que las agencias obtengan o reúnan información para llevar a cabo tal finalidad. ${ }^{26} \mathrm{~A}$ este respecto, la literatura se refiere a la "detección" como la manera de obtener información acerca del comportamiento indeseable e incumplidor de la regulación. ${ }^{27} \mathrm{La}$ actividad de descubrir los incumplimientos es el primer paso en el esquema de cumplimiento regulatorio ${ }^{28}$ y se encuentra sujeta a una restricción basal, consistente en que no existen los recursos económicos ni el personal para detectar toda clase de inobservancias, por lo que, evidentemente, no todas las infracciones serán

\footnotetext{
${ }^{25}$ Debe señalarse que esta forma de enfrentar los poderes del servicio también ha operado en sede jurisdiccional, como ha acontecido a propósito de la facultad del SERNAC para ejercer directamente acciones por infracción a la LPDC, sin que exista un juicio en marcha ni denunciante particular, invocando el interés general de los consumidores. Según la Corte de Apelaciones de Santiago, 10 de julio de 2013, Rol No 1715-2012, considerando 50: "al SERNAC le asiste como función esencial el velar por la protección de los 'intereses generales de los consumidores', y dentro de este entendido es menester que cuente con la habilitación procesal para ejercer las acciones que el legislador ha puesto bajo su amparo. El interpretarlo de modo diverso - y en un sentido restringido- significaría que en la práctica el SERNAC carecería de las herramientas necesarias para cumplir de la debida forma con la función que la ley le ha entregado, no habiendo sido ésta la intención que el legislador tuvo en cuenta para establecer una legislación protectora y cautelar de los derechos de los consumidores". Un comentario a esta sentencia en IsLER, Erika, "La facultad del Servicio Nacional del Consumidor para denunciar infracciones a la Ley No 19.496 (Corte de Apelaciones de Santiago)", Revista de Derecho (Valdivia), 2014, Vol. XXVII, No 1, pp. 255 y ss.

${ }^{26}$ BLACK, Julia, "Critical Reflections on Regulation", Australian Journal of Legal Philosophy, 2002, $\mathrm{N}^{\circ} 27$, p. 26.

${ }^{27}$ Baldwin, Robert; CAve, Martin; Lodge, Martin, Understanding Regulation. Theory, Strategy and Practice, Oxford University Press, Oxford, 2012, 2a edición, p. 227.

${ }^{28}$ Baldwin; CAVE; Lodge, cit. (n. 27), p. 227.
} 
corregidas. ${ }^{29}$ Un problema adicional se halla en la posible manipulación de información por parte del regulado, o bien, su empleo estratégico, lo cual significa que el respectivo órgano se encuentra en una posición asimétrica en la obtención de la información para detectar un incumplimiento normativo. ${ }^{30}$

Las agencias tienen distintas maneras para obtener información acerca del cumplimiento de las normas que se hallan bajo el ámbito de su competencia. En el caso de Chile, y sin que sea exhaustivo, los mecanismos usuales de detección son los requerimientos de información a los regulados; $; 1$ inspecciones; ${ }^{32}$ citación a los administrados o sus representantes (en caso de ser personas jurídicas), para que declaren sobre ciertos hechos; ${ }^{33}$ divulgación de información legalmente ordenada; ${ }^{34}$ o la recepción de denuncias. ${ }^{35}$ Estos instrumentos son valiosos en un diseño institucional donde existe una agencia a cargo de promover el cumplimiento regulatorio. Si tales herramientas no existen, son débiles o escasas, el órgano respectivo difícilmente podrá satisfacer los objetivos públicos cuya obtención el legislador le ha impuesto. ${ }^{36}$ Por su parte, la ausencia de capacidad técnica en el análisis de la información, o bien, una falta de solvencia para discernir entre información de buena calidad y otra que no la tiene, ${ }^{37}$ puede generar dificultades adicionales a la detección de los incumplimientos. ${ }^{38}$

${ }^{29}$ Baldwin, Robert; Black, Julia, "Really Responsive Regulation", LSE Law - Society Economy Working Papers, 2007, No 15, p. 27. Esto es un asunto estructural: en general las agencias "no tienen los recursos para concretar cada función delegada por la legislación”, como lo sostiene Hawkins, Keith; Thomas, John, "The Enforcement Process in Regulatory Bureaucracies", en: Hawkins, Keith; Thomas, John (eds.), Enforcing Regulation, Kluwer-Nijhoff Publishing, Boston, 1984, p. 11.

${ }^{30}$ Veljanowski, Cento, "Strategic Use of Regulation", en: Baldwin, Robert; CAVE, Martin; LodGe, Martin (eds.), The Oxford Handbook of Regulation, Oxford University Press, Oxford, 2013, p. 94.

${ }^{31}$ Por ejemplo, en el artículo $3^{\circ}$ letra e) y m) de la Ley $N^{o} 20.417,2010$.

${ }^{32}$ Clásicamente, en los artículos 155 y ss. del Código Sanitario.

${ }^{33}$ Así, en el artículo 29 de la Ley No 20.417, 2010.

${ }^{34}$ Como los hechos esenciales, en lo que respecta a entidades inscritas en el Registro de Valores de la Comisión para el Mercado Financiero, según el artículo 10 de la Ley Nº 18.045, 1981.

${ }^{35}$ Entre otros órganos, es lo que acontece con la Dirección del Trabajo, de acuerdo con lo establecido en el artículo 42 del DFL N ${ }^{\circ} 2,1967$.

${ }^{36}$ Ya lo escribió el maestro Duguit, Léon, Law in the Modern State, George Allen \& Unwin Ltd., Londres, 1921, p. 39: la función social en el Derecho público consiste en que quienes detentan potestades públicas se hallan en la obligación de asegurar, sin interrupción, la satisfacción de las tareas encomendadas.

${ }^{37}$ A propósito de la recepción de información de buena y mala calidad, véase la mención en BALDWIN; CAve; Lodge, cit. (n. 27), p. 228.

${ }^{38} \mathrm{La}$ incompetencia en el ejercicio de las funciones públicas es una falla del Estado, como lo ha dicho Stiglitz, Joseph, “Government Failure vs. Market Failure: Principles of Regulation”, en: BaLleisen, Edward; Moss, David (eds.), Government and Markets: Toward a New Theory of Regulation, Cambridge 


\section{Derecho constitucional de petición ante la Administración}

La Constitución Política de la República establece, en su artículo 19 numeral $14^{\circ}$, el derecho constitucional de petición ante la autoridad, que puede recaer "sobre cualquier asunto de interés público o privado", y cuyo único límite es "proceder en términos respetuosos y convenientes." Este derecho "permite que las personas hagan conocer a la autoridad competente respectiva, preocupaciones, necesidades y propuestas expresadas fuera de los recursos administrativos y de los procedimientos legislativos y judiciales formalizados". ${ }^{39}$ Este derecho genera la obligación correlativa de la autoridad de dar recepción, examinar y responder aceptando o rechazando, la solicitud que el particular ha efectuado. ${ }^{40}$

Desde el punto de vista de la Administración del Estado, la doctrina ha defendido el deber de respuesta por parte del respectivo órgano, que se sanciona penal (artículo $158 \mathrm{~N}^{\circ} 4^{\circ}$ del Código Penal) y administrativamente (artículo 84 letra e) del Estatuto administrativo) en caso de obstruírsele. ${ }^{41}$ Pero, además, existe no poca jurisprudencia de la CGR respecto al derecho de petición, incluso para temas tan sensibles como la toma de razón, admitiendo presentaciones que, si bien, no se hallan contempladas en su estatuto orgánico ni en la Constitución, han de ser consideradas como ejercidas en el marco de aquel derecho. ${ }^{42}$

Conforme a los pronunciamientos de la entidad contralora, el derecho de petición constitucionalmente asegurado que los particulares pueden ejercer ante la Administración, a saber: (i) que los órganos respondan la

\footnotetext{
University Press, New York, 2009, p. 17.

${ }^{39}$ NOGUEIRA, Humberto, "El derecho constitucional de petición y su insuficiente regulación legislativa", Revista de Derecho (Coquimbo), 2008, vol. 15, N², p. 92.

40 NogueIRA, cit. (n. 39), pp. 93 y 98.

${ }^{41}$ Como lo explica Aguerrea, Pedro, "El Derecho de petición ante la Administración del Estado: acerca de la obligación de respuesta", Ius Publicum, 2002, N 9, pp. 55-70.

${ }^{42}$ Contraloría General de la República, dictamen $\mathrm{N}^{\circ}$ 47.272, 9 de octubre de 2002, según el cual, "cuando particulares concurren a la Contraloría General a propósito del trámite de toma de razón para hacer ver sus planteamientos, no actúan en ejercicio de un derecho especialmente otorgado al efecto, sino sólo haciendo uso del derecho a formular peticiones a la autoridad que reconoce el artículo 19 № 14 de la Carta Suprema." La referencia y explicación, en CORDERO VEGA, Luis, "La jurisprudencia administrativa en perspectiva: entre legislador positivo y juez activista. Comentario desde el dictamen sobre la píldora del día después", en: Couso, Javier (ed.), Anuario de Derecho público, Universidad Diego Portales, Santiago, 2010, pp. 182-183.
} 
solicitud del particular; ${ }^{43}$ (ii) que se resuelva dentro de un plazo prudencial; ${ }^{44}$ (iii) que se notifique la decisión al peticionario; ${ }^{45}$ (iv) que lo pedido se halle dentro del ámbito de competencia de la respectiva agencia; ${ }^{46}$ (v) que se haga en términos respetuosos y convenientes ${ }^{47}(\mathrm{v})$ ha de constar por escrito $;{ }^{48} \mathrm{e}$ (vi) incluso puede ser ejercido anónimamente bajo la forma de "denuncias", tratándose de presentaciones ante la CGR. ${ }^{49}$

Por último, la Ley Orgánica Constitucional de Bases Generales de la Administración del Estado establece que "(l)os órganos de la Administración del Estado actuarán por propia iniciativa en el cumplimiento de sus

\footnotetext{
${ }^{43}$ Contraloría General de la República, dictamen No 84.724, 23 de noviembre de 2016: “(...) de acuerdo con lo establecido en el artículo $19 \mathrm{~N}^{\circ} 14$ de la Constitución Política, la recurrente tiene derecho a realizar las presentaciones que estime pertinentes a la autoridad, procediendo en términos respetuosos y convenientes, quien, a su vez, se encuentra en el imperativo de dar respuesta oportuna a dichas solicitudes por escrito y formalmente (...)."

${ }^{44}$ Contraloría General de la República, 4 de octubre de 2016, dictamen $N^{\circ} 72.369$ : "el requerimiento de que se trata ha sido formulado conforme a lo prescrito en el artículo 19, $\mathrm{N}^{\circ} 14$, de la Constitución Política, según el cual toda persona puede presentar peticiones a la autoridad, por lo que aquella se encuentra en el deber de acoger o denegar la solicitud, otorgándose, dentro de un plazo prudencial (...)”. En este pronunciamiento, agrega la CGR que, ante la incompetencia para resolver una solicitud vía derecho de petición, el órgano debe, "en cumplimiento de lo dispuesto en el inciso segundo del artículo 14 de la ley $\mathrm{N}^{\circ} 19.880$, enviar de inmediato los antecedentes a la autoridad que deba conocer del asunto según el ordenamiento jurídico, informando de ello al interesado.”

${ }^{45}$ La CGR ordena que el derecho de petición opera "dándoles debido conocimiento de la respuesta" a los peticionarios (Contraloría General de la República, 21 de noviembre de 2011, dictamen $\mathrm{N}^{\circ}$ 59.778), o bien, "dándose debido conocimiento de la respuesta al solicitante" (Contraloría General de la República, 23 de abril de 2010, dictamen $\mathrm{N}^{\circ} 21.480$ ).

${ }^{46}$ Contraloría General de la República, 21 de noviembre de 2011, dictamen No 59.778: “el derecho de petición consagrado en el artículo 19, $\mathrm{N}^{\circ}$ 14, de la Constitución Política de la República, conlleva la obligación de los entes públicos de responder a las solicitudes de los administrados lo que en derecho proceda, (...), o bien, en el evento de carecer de competencia, limitarse a declarar ese hecho (...)".

${ }^{47}$ Así lo ha dicho la Contraloría, entre otros, en Contraloría General de la República, 3 de octubre de 2018, dictamen $\mathrm{N}^{\circ}$ 24.828: "se hace presente que para eventuales futuras solicitudes, el peticionario deberá dar cumplimiento a lo dispuesto en el artículo $19, \mathrm{~N}^{\circ} 14$, de la Constitución Política de la República, que asegura a todas las personas el derecho de presentar peticiones a la autoridad, sobre cualquier asunto de interés público o privado, sin otra limitación que la de proceder en términos respetuosos y convenientes, condición que no fue cumplida en la especie. (...)”.

${ }^{48}$ Por ejemplo, entre muchísimos, señala en Contraloría General de la República, 23 de abril de 2010, dictamen $\mathrm{N}^{\circ} 21.480$, que la respuesta del órgano, "por razones de certeza y buena técnica administrativa debe constar por escrito".

${ }^{49}$ Contraloría General de la República, 14 de noviembre de 2018, dictamen No 23.314: "en virtud del derecho de petición consagrado en el artículo 19, $\mathrm{N}^{\circ} 14$, de la Constitución Política, a toda persona le asiste el derecho de efectuar denuncias ante esta Entidad de Control por eventuales irregularidades ocurridas en actuaciones de los órganos de la Administración del Estado, las que, de conformidad con el dictamen $\mathrm{N}^{\circ} 14.868$, de 2017 , de este origen, entre otros, pueden ser formuladas bajo la modalidad de reserva de identidad con la finalidad de proteger al requirente y no inhibir su realización."
} 
funciones, o a petición de parte cuando la ley lo exija expresamente $o$ se haga uso del derecho de petición o reclamo", ${ }^{50}$ de manera que -por si existía alguna duda-, según la ley, quedan los órganos administrativos convocados a actuar si así lo pide un particular ejerciendo su derecho de petición. Asimismo, el deber de respuesta ante tal solicitud se reafirma con la Ley $\mathrm{N}^{\mathrm{o}} 19.880$, que ordena a la Administración a resolver el fondo del asunto que se le ha planteado, conforme al principio conclusivo contenido en el artículo $8^{\circ}$ de ese cuerpo normativo. ${ }^{51}$

\section{El SERNAC ante el TC}

\subsection{Lo que el TC declaró inconstitucional}

El TC decidió, en el control de constitucionalidad del proyecto de ley que fortalecía al SERNAC, en lo pertinente para este estudio, las siguientes inconstitucionalidades: (i) del nuevo artículo 58 letra o) que otorgaba competencia al servicio para resolver la mediación y conciliación individual ${ }^{52}$ (ii) del párrafo que se titulaba: "De la mediación individual, de la conciliación y del procedimiento sancionatorio instruido por el Servicio Nacional del Consumidor"; 53 y (iii) del nuevo artículo $50 \mathrm{G}$ que desarrollaba procedimentalmente, en sus efectos y sanción, la mediación y conciliación individual. ${ }^{54}$ Para el TC, el proyecto vulneraba la Constitución porque el SERNAC asumiría facultades jurisdiccionales y, además, sin imparcialidad, lo que contravendría los artículos 76 y $19 \mathrm{~N}^{\circ}$ 3 de la Constitución. ${ }^{55}$ Específicamente, afirma la revisión constitucional que la conciliación es una potestad jurisdiccional: "con el Proyecto dicho servicio público asumiría -además- potestades jurisdiccionales para arbitrar conciliaciones, (...) en circunstancias que tales medidas sólo pueden ser adoptadas por un tribunal independiente e imparcial,

\footnotetext{
${ }^{50}$ Artículo $8^{\circ}$ del DFL No $1 / 19.653,2001$.

${ }^{51}$ Artículo $8^{\circ}$ de la Ley $N^{\circ} 19.880,2003$ : "Principio conclusivo. Todo el procedimiento administrativo está destinado a que la Administración dicte un acto decisorio que se pronuncie sobre la cuestión de fondo y en el cual exprese su voluntad."

52 Tribunal Constitucional, 18 de enero de 2018, cit. (n. 2), considerando $40^{\circ}$, letra b).

${ }^{53}$ Tribunal Constitucional, 18 de enero de 2018, cit. (n. 2), considerando $40^{\circ}$, letra c).

54 Tribunal Constitucional, 18 de enero de 2018, cit. (n. 2), considerando $40^{\circ}$, letra d).

55 Tribunal Constitucional, 18 de enero de 2018, cit. (n. 2), considerando $33^{\circ}$.
} 
características que éste no reúne". ${ }^{56}$ Enseguida, asevera el fallo que, en el proyecto, el SERNAC:

"se erige en instancia de mediación; arbitra a continuación una audiencia obligatoria de conciliación (artículo $50 \mathrm{G}$ ); para concluir pudiendo ordenar el cese de las conductas infractoras, la restitución de los cobros que le parezcan improcedentes, así como adoptar indeterminadas medidas para evitar supuestas infracciones futuras (artículo $50 \mathrm{~N}$ ), al modo de una sentencia que acoge una acción de amparo, y en que un juez cumple las funciones conservadoras que le atribuye el artículo $3^{\circ}$ del Código Orgánico de Tribunales". ${ }^{57}$

Para el TC, "todo este conjunto de antecedentes, analizados y concatenados entre sí, revelan inequívocamente que en estos casos el Servicio Nacional del Consumidor entraría a ejercer 'jurisdicción'(...)". ${ }^{58}$ Esto significa que es la mediación y conciliación individual obligatoria, tal como venía concretamente configurada en el proyecto -lo que el TC, junto a otros mecanismos, refiere como "estos casos"- aquellos que importan una actividad jurisdiccional que es, en la especie, inconstitucional.

La sentencia sostiene que el lugar en que "naturalmente corresponde" resolver las contiendas entre proveedores y consumidores es la sede jurisdiccional, de modo privativo y excluyente, ${ }^{59}$ agregando-específicamente en lo que concierne a las sanciones administrativas, debe advertirse- - que la fiscalización y sanción administrativa deben separarse para satisfacer el artículo $19 \mathrm{~N}^{\mathrm{o}} 3^{\circ}$ de la Carta, referido al justo y racional procedimiento. ${ }^{60} \mathrm{~A}$ juicio del TC, el SERNAC es un órgano sesgado y, por lo tanto, no puede ser imparcial en la resolución de los conflictos entre proveedores y consumidores ("debe tratarse de un tercero independiente e imparcial"). ${ }^{61}$ Tal falta de imparcialidad obedece a que, de acuerdo con el proyecto de ley:

"el Servicio Nacional del Consumidor puede representar individualmente a los consumidores en las causas que se inicien ante los tribunales de justicia para la determinación de las indemnizaciones de

\footnotetext{
56 Ídem.

${ }^{57}$ Ibídem, considerando $35^{\circ}$.

${ }^{58}$ Ibídem, considerando $36^{\circ}$.

${ }^{59}$ Tribunal Constitucional, 18 de enero de 2018, cit. (n. 2), considerando $37^{\circ}$.

60 Ídem.

${ }^{61}$ Ibídem, considerando $38^{\circ}$.
} 
perjuicios correspondientes (artículo 8 letra e) como realizar, a solicitud de un consumidor, mediaciones individuales (artículo 8 letra h). Estas atribuciones, mencionadas a vía ejemplar, demuestran inequívocamente que nos encontramos frente a un órgano de la Administración que interviene en la relación entre consumidores y proveedores de un servicio representando los intereses de una de las partes, lo que le resta las condiciones indispensables de independencia e imparcialidad con que debe enfrentarse el ejercicio de la jurisdicción". ${ }^{62}$

Dos cosas deben indicarse sobre este considerando. La primera de ellas es que hay un error craso del TC porque estas facultades del artículo $8^{\circ}$ están específica y expresamente referidas a las asociaciones de consumidores y no al SERNAC. La segunda observación (relevante para este texto) es que el TC sostiene que esta clase de atribuciones, como llevar a cabo una mediación individual, es una forma de representar los intereses del consumidor. De ahí que sea improcedente "que el mismo servicio estatal llamado a proteger a una de las partes lucrativamente interesadas, los consumidores, sea instituido como árbitro supremo, para luego dirimir los contenciosos e impugnaciones que enderecen contra sus proveedores". ${ }^{63}$ Es decir, lo que según el TC compromete la imparcialidad del servicio es su capacidad de arbitrar o dirimir conflictos, cuestión que en la mediación y conciliación individual a la que el TC específicamente se está refiriendo, tal como venía diseñada en el proyecto, obedece a la obligatoriedad de la instancia, garantizada incluso mediante multas, así como el establecimiento unilateral de bases de arreglo por el SERNAC a las que forzosamente debían responder las partes.

5.2. Lo que el TC no declaró inconstitucional y las sentencias Roles $\mathrm{N}^{\mathrm{o}} 251$ y No 411

En lo que respecta a la sentencia del $\mathrm{TC}$ que se viene revisando, es claro que el antiguo 58 inciso $2^{\circ}$ letra $\mathrm{f}$ ) no fue aludido de ninguna manera por la sentencia; y no tenía cómo ser objeto de la revisión de constitucionalidad, pues, el control preventivo versaba, entre otras, sobre las reglas que lo sustituían. Ahora bien, debe advertirse que el TC, como se sabe, no declaró inconstitucional el procedimiento voluntario para la

\footnotetext{
62 Ídem.

63 Ídem.
} 
protección del interés colectivo o difuso de los consumidores, a pesar de que consideró materia de ley orgánica constitucional y, en consecuencia, sujetos al control de constitucionalidad, los artículos $54 \mathrm{H}$ y $54 \mathrm{P}$ del proyecto de ley, ${ }^{64}$ por radicar funciones jurisdiccionales en el SERNAC. ${ }^{65}$ La primera disposición establece los aspectos básicos de la instancia (descripción, iniciación, notificación y suspensión de la prescripción de la denuncia y acciones), y la segunda regula la resolución de término del procedimiento voluntario. Ambas normas fueron expresamente consideradas conformes con la Constitución, ${ }^{66}$ como también aconteció con el artículo 54 Q que regula el efecto erga omnes del acuerdo en el procedimiento en comento previa aprobación del juez. ${ }^{67}$

Por último, se hace necesario indicar que el TC, en otra ocasión, se había pronunciado sobre los reclamos ante el SERNAC, la comunicación al proveedor, las propuestas de solución voluntaria, la promoción del entendimiento voluntario entre las partes operado por el servicio y el carácter de transacción extrajudicial del acuerdo. En efecto, la LPDC, en su versión original, regulaba estas materias en el inciso $2^{\circ}$ de su artículo 50, como más arriba se ha explicado ${ }^{68}$ Esta regla fue específicamente enviada al control de constitucionalidad preventivo ante el TC, determinado este órgano que no se trataba de normas propias de ley orgánica constitucional ${ }^{69}$ $\mathrm{y}$, en consecuencia, no debía existir pronunciamiento al respecto. ${ }^{70}$ Por lo mismo, cuando la Ley $\mathrm{N}^{\mathrm{o}} 19.955$ trasladó la mediación individual al artículo 50 f), ${ }^{71}$ no se envió dicha modificación para control ante el TC, como queda claro al revisar la STC Rol No 411, de 2004. ${ }^{72}$

\footnotetext{
${ }^{64}$ Tribunal Constitucional, 18 de enero de 2018, cit (n. 2), considerando $28^{\circ}$.

${ }^{65}$ Ibídem, considerando $29^{\circ}$.

${ }^{66}$ Ibídem, considerando $32^{\circ}$.

${ }^{67}$ Ídem. Esta disposición fue precisamente sometida a control preventivo por la Cámara de Diputados.

${ }^{68}$ Véase, más arriba, la parte III, sección 1.

${ }^{69}$ Tribunal Constitucional, 27 de enero de 1997, Rol No 251, considerando $8^{\circ}$ : "las disposiciones contenidas en el inciso segundo del artículo 50 del proyecto remitido, no son propias de ley orgánica constitucional, según se desprende de la interpretación que deriva de su texto, de la naturaleza de las leyes orgánicas constitucionales dentro de nuestra normativa jurídica y del espíritu del constituyente al incorporarlas a nuestra Carta Fundamental(.)".

${ }^{70}$ Tribunal Constitucional, 27 de enero de 1997, cit. (n. 69), $\mathrm{N}^{\circ} 3$ de la parte resolutiva.

${ }^{71}$ Numeral 27) del Artículo único de la Ley No 19.955, 2004.

${ }^{72}$ Tribunal Constitucional, 27 de junio de 2004, Rol No 411.
} 
V. ADMISIBILIDAD DE LA RECEPCIÓN DE RECLAMOS, SU COMUNICACIÓN AL PROVEEDOR Y LA PROMOCIÓN DE UN ENTENDIMIENTO VOLUNTARIO

Como se ha dicho en este texto, la cuestión consiste en dilucidar si el SERNAC puede implementar la recepción de reclamos, comunicarlos al proveedor y promover un entendimiento voluntario entre proveedores $\mathrm{y}$ consumidores, contenidas en el antiguo artículo 58 inciso $2^{\circ}$ letra f) de la LPDC, a pesar de su derogación, y de la declaración de inconstitucionalidad, por parte del TC, de la denuncia, mediación voluntaria y conciliación individual, establecida en los fallidos artículos $50 \mathrm{G}$ y 58 inciso $2^{\circ}$ letra o) del proyecto de reforma. Con los elementos de juicio previamente articulados, es posible responder positivamente la interrogación planteada.

\section{Constitucionalidad de recibir reclamos y promover un entendimiento voluntario}

Respecto a la constitucionalidad de la recepción de reclamos y mediar individualmente, es importante subrayar que lo que fue objeto del control de constitucionalidad por parte del TC fueron disposiciones que tenían una específica configuración y como tales, declaradas inconstitucionales. En efecto, no se trata de que el SERNAC no pueda recibir denuncias ni mediar individualmente como cuestión abstracta, sino que no puede hacerlo conforme a la regulación que contenían las normas del proyecto, que fueron declaradas inconstitucionales. Es eso lo que, a juicio del TC, torna jurisdiccionales las funciones y por eso las declara materia de ley orgánica para controlarlas.

Las nuevas normas, como se dijo, (i) establecían una denuncia del proveedor que tenía una doble función, a saber, iniciaba el procedimiento sancionatorio y generaba la mediación individual; (ii) compelían al proveedor, bajo sanción de multa, a proponer soluciones o correcciones dentro del plazo de siete días hábiles; (ii) otorgaba carácter de transacción extrajudicial al acuerdo en la mediación individual; (iii) establecía una conciliación obligatoria; (iv) obligaba a las partes sobre las bases de arreglo concretas formuladas unilateralmente por el SERNAC; y (v) daba mérito ejecutivo al acuerdo en la mediación y en la conciliación. Este mecanismo 
era completamente diferente, según se destacó, ${ }^{73}$ al del derogado 58 inciso $2^{\circ}$ letra f) de la LPDC.

Lo anterior se entiende mejor si se observa que, cuando el mismo TC controló el artículo 50 inciso $2^{\circ}$ en el texto original de la LPDC, decidió que ésta no era una materia sujeta a la revisión de constitucionalidad por no formar parte de lo que debe regular la ley orgánica constitucional sobre la organización y atribuciones de los tribunales. Y no lo era porque esta disposición, que acabó siendo el artículo 58 inciso $2^{\circ}$ letra f) de la LPDC por obra de la Ley $\mathrm{N}^{0} 19.955$, no podía considerarse jurisdiccional, puesto que recibir reclamos, comunicarlos, no obligar al proveedor a presentar soluciones y promover una solución voluntaria no son materias que puedan corresponder al Poder Judicial. Además, por definición, la transacción "extrajudicial" entre privados no es una cuestión jurisdiccional, ${ }^{74}$ por más que produzca el efecto de cosa juzgada, ${ }^{75}$ siempre que las bases de arreglo no sean impuestas.

Es decir, lo que el SERNAC no puede hacer, de acuerdo con el TC, es ejercer funciones judiciales y, de acuerdo con el mismo órgano de control de constitucionalidad, las atribuciones del artículo 58 inciso $2^{\circ}$ letra f) derogado (que originalmente estaban en el artículo 50 de la LPDC) no lo eran, siendo decisiva su obligatoriedad, como lo muestra la circunstancia de que el TC no declarara inconstitucional el procedimiento colectivo de acuerdos entre proveedores y consumidores que, a pesar de ser considerado jurisdiccional, no es obligatorio, como sí lo eran la mediación y conciliación individuales en el proyecto. En tal sentido, la existencia de un mecanismo no obligatorio de resolución de conflicto entre proveedor y consumidor es constitucional.

La revisión de la jurisprudencia constitucional permite concluir que, en abstracto, no hay inconstitucionalidad en que el SERNAC reciba reclamos; que estos le sean notificados al proveedor para que acuda voluntariamente ante el servicio y proponga soluciones; que el servicio promueva un entendimiento voluntario entre las partes; el carácter transaccional del documento del acuerdo; y que se extinga la responsabilidad contravencional (con las particularidades que más abajo se indicarán). Estas no son

\footnotetext{
${ }^{73}$ Véase, más arriba, la Parte III, sección 3.

${ }^{74}$ En igual sentido, Aimone, Enrique, Derecho de protección al consumidor, Editorial Jurídica Conosur, Santiago, 1998, p. 178.

${ }^{75}$ De acuerdo con el artículo 2.460 del Código Civil: "La transacción produce el efecto de cosa juzgada en última instancia; pero podrá impetrarse la declaración de nulidad o la rescisión, en conformidad a los artículos precedentes."
} 
actividades jurisdiccionales según el propio TC y no son inconstitucionales al no ser obligatorias.

\section{Reclamar y solicitar que el SERNAC comunique el reclamo y promueva un} entendimiento voluntario es una manifestación del derecho constitucional de petición

Continuando con el análisis desde la perspectiva constitucional, resulta claro, a la luz de la exposición en torno al derecho constitucional de petición y su configuración en sede administrativa, que efectuar una solicitud ante un órgano de la Administración, dentro de su ámbito de competencia, no puede encontrarse prohibido. De ahí que tenga cobertura constitucional acudir ante el SERNAC, con el objeto de que, respecto a la petición que un consumidor efectúe, el servicio ejerza su función general de "(v)elar por el cumplimiento de las disposiciones legales y reglamentarias relacionadas con la protección de los derechos de los consumidores", con arreglo al artículo 58 inciso $2^{\circ}$ letra g) de la LPDC. Por lo tanto, un consumidor que solicita protección, ante el SERNAC, reclamando y requiriendo que este órgano traslade el reclamo y solicite que el proveedor voluntariamente acceda a una solución, lo hace en su calidad de titular de un derecho constitucional que, como no se encuentra regulado ni configurado en la ley, opera solamente bajo las limitaciones que se han visto más arriba: ha de ejercerse de manera respetuosa y conveniente. A su vez, desde el punto de vista del órgano administrativo, este debe dar una respuesta, dentro de un plazo prudencial, y quedar registrado por escrito, como lo ha señalado la CGR.

En este escenario, que el SERNAC implemente un canal estandarizado, si se quiere- por medio del cual reciba las peticiones de los consumidores y comunique a los proveedores tal situación para que, si estos lo estiman, solucionen el reclamo, y el servicio promueva el arreglo, es una manera de cumplir con los principios de eficiencia y eficacia contenidos en el artículo $3^{\circ}$ inciso $2^{\circ}$ de la Ley Orgánica Constitucional de Bases Generales de la Administración del Estado, considerando que la realidad indica que no se trata de requerimientos aislados, sino que se presentan en gran volumen. ${ }^{76}$

76 Véase, por ejemplo, Servicio Nacional del Consumidor, "Reporte estadísticos de reclamos", en línea: https://www.sernac.cl/portal/619/articles-4093_archivo_01.pdf, 2 de diciembre de 2018. En este documento se explica que los reclamos ingresados el primer semestre del 2014 corresponde a 143.216. Más recientemente, sólo en el mercado de telecomunicaciones, se constata que, en el primer semestre de 2018, los reclamos ascienden a 54.537. Véase: Servicio NACiOnAl DEl Consumidor, "Ranking de 
Fijar un esquema de tramitación de las solicitudes, que pueden tener la nomenclatura "reclamos" u otra denominación es, simplemente, una forma de facilitar el ejercicio del derecho de petición. Ha de recordarse aquí, además, que, como se dijo, la recién señalada Ley Orgánica Constitucional de Bases Generales de la Administración del Estado establece, en su artículo $8^{\circ}$, que el derecho de petición es una de las formas de impulsar el deber de actuación de la Administración del Estado, lo cual debe hacerse, además, según esa misma disposición, "procurando la simplificación y rapidez de los trámites", cuestión que abona en favor de una tramitación expedita de las solicitudes de los consumidores ante el SERNAC. De lege lata, además, la solicitud de un consumidor ante la agencia se encuentra establecida para un específico efecto jurídico, a saber, suspender la prescripción, lo que opera "por requerir el afectado la intervención del Servicio(.)". ${ }^{77}$

\section{Recibir reclamos, comunicarlos al proveedor y promover un entendimiento voluntario entre consumidores y proveedores son potestades implícitas}

$\mathrm{Si}$, por una parte, no es inconstitucional que el SERNAC reciba los reclamos y promueva un entendimiento voluntario entre consumidor $\mathrm{y}$ proveedor, puesto que no se trata de una materia jurisdiccional ni obliga a las partes; y, por otro lado, es constitucional que un consumidor requiera al servicio en estos términos porque ejerce su derecho constitucional de petición, corresponde preguntarse si el servicio tiene habilitación legal para implementar un mecanismo tal. Es lo que se argumenta en las líneas que siguen.

Como primera cuestión, ya se ha visto que el SERNAC posee una función general consistente en "velar por el cumplimiento de las disposiciones de la (LPDC) y demás normas que digan relación con el consumidor", ${ }^{78}$ que se reitera como función especial del servicio en la misma ley, ${ }^{79}$ debiendo este "(v)elar por el cumplimiento de las disposiciones legales y reglamentarias

Reclamos Telecomunicaciones", en línea: https://www.sernac.cl/portal/619/articles-54978_archivo_01. pdf, 2 de diciembre de 2018. Sobre la resolución alternativa de conflictos en línea en materia de consumo y sus ventajas desde la perspectiva europea, puede verse la experiencia relatada en BujosA, Lorenzo; PAlomo, Diego, "Mediación electrónica: Perspectiva europea", Ius et Praxis, 2017, Año 23, $\mathrm{N}^{\circ} 2$, pp. 63 y ss.

${ }^{77}$ Artículo 26 de la Ley No 19.496, 1997.

${ }^{78}$ Artículo 58 inciso $1^{\circ}$ de la Ley No $19.496,1997$.

${ }^{79} \mathrm{El}$ artículo 58 inciso $2^{\circ}$ de la Ley $\mathrm{N}^{\circ}$ 19.496, 1997, prescribe: “(c)orresponderán especialmente al Servicio Nacional del Consumidor las siguientes funciones: (...)”. 


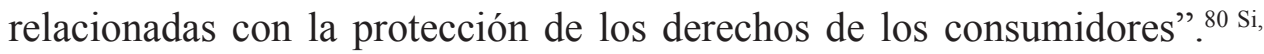
según lo señalado en este trabajo, se encuentra reconocido que tales cláusulas expresas se deben interpretar teleológicamente e incluyen potestades que no se hallan explícitamente fijadas en la ley, ${ }^{81}$ tal como lo ha reconocido la CGR y el Poder judicial, puede considerarse la recepción de reclamos, su comunicación al proveedor y la promoción de un entendimiento voluntario como medios para satisfacer tal función, que es un núcleo esencial de la finalidad estatal de proteger los derechos de los consumidores, radicada por el legislador en el SERNAC.

En estos términos, recibir reclamos, trasladarlos al proveedor y generar una instancia no obligatoria entre las partes de la relación de consumo son potestades inherentes que tienen cobertura legal en el artículo 58 incisos $1^{\circ}$ y $2^{\circ}$ letra g) de la LPDC, además -nuevamente- de los principios de eficiencia y eficacia de la Ley Orgánica Constitucional de Bases Generales de la Administración del Estado, más arriba aludidos, así como del deber de resolver el fondo de lo pedido por el consumidor. Adicionalmente, la función general de velar por las disposiciones que protejan a los consumidores o digan relación con él es, simplemente, una técnica de habilitación poco intensa que debe entenderse como una concesión al órgano de la Administración de un amplio campo para decidir qué hacer. Mientras más baja la densidad de la regulación, más poder se concede al órgano y viceversa. ${ }^{82}$

En segundo lugar, existen otras atribuciones expresamente entregadas al SERNAC respecto a las cuales, específicamente, la recepción de reclamos es un medio. Es lo que acontece con la potestad fiscalizadora del servicio, que ha sido reforzada por la Ley $\mathrm{N}^{\mathrm{o}} 21.081$ y cuya regulación, principalmente, se halla en el artículo 58 inciso $2^{\circ}$ letra a) de la LPDC luego de su reforma. Al respecto, el legislador ha ordenado que la fiscalización se efectúe sobre la base de un plan anual que debe priorizar "aquellas áreas que involucren un mayor nivel de riesgo para los derechos de los consumidores". ${ }^{83}$ Para detectar tales riesgos de incumplimiento, se necesita -según antes se señaló desde la perspectiva del Derecho regulatorio- información, una de cuyas fuentes

\footnotetext{
${ }^{80}$ Artículo 58 inciso $2^{\circ}$ letra g), Ley No 19.496, 1997.

${ }^{81}$ En igual sentido, IsLER, cit. (n. 8), p. 1132.

${ }^{82}$ Lo que ha sido explicado en Guiloff, Matías, "Operativizando la relación ley-reglamento: una propuesta de redefinición del rol de la reserva legal", Revista de Derecho (Valdivia), 2012, Vol. XXV, $\mathrm{N}^{\mathrm{o}} 1$, pp. 130-133.

${ }^{83}$ Artículo 58 inciso $2^{\circ}$ letra a), Ley $\mathrm{N}^{\circ}$ 19.496, 1997.
} 
son, precisamente, los requerimientos efectuados por los consumidores al SERNAC con ocasión de lo que consideran una afectación de sus derechos. Estos reclamos son relevantes porque aumentan el volumen de información del servicio sobre los incumplimientos, considerando la escasez de recursos de los órganos administrativos para detectar las inobservancias a la regulación. Por lo tanto, es posible sostener que existe cobertura legal expresa referida a la fiscalización, siendo inherente la atribución de recibir reclamos para promover un modelo de cumplimiento regulatorio que exige la evaluación de los riesgos en la planificación de la actividad fiscalizadora. ${ }^{84}$

En la misma línea, otras potestades expresas para las que también la recepción de reclamos es un instrumento, son, por ejemplo: (i) la citación a declarar a los representantes y dependientes de un proveedor, así como a toda persona que haya participado o conozca hechos relevantes para la resolución de un procedimiento (judicial) sancionatorio; ${ }^{85}$ (ii) la reunión, elaboración, procesamiento, divulgación y publicación de información dirigida al consumidor; ${ }^{86}$ (iii) la realización de estudios en el área del consumo, ${ }^{87}$ (iv) la solicitud de documentos o antecedentes necesario para fines de fiscalización; ${ }^{88}$ y (v) la solicitud de antecedentes y documentación relacionados con la información básica comercial. ${ }^{89}$

\section{Referencia a la transacción y extinción de la responsabilidad contravencional}

Como se recordará, el derogado artículo 58 inciso $2^{\circ}$ letra f) de la LPDC establecía dos efectos en caso de existir un acuerdo entre proveedor y consumidor, a saber, en primer lugar, se producía una transacción y, en segundo término, se extinguía la responsabilidad contravencional del proveedor. Estas

\footnotetext{
${ }^{84}$ Debe advertirse, sin embargo, que el argumento que se viene planteando respecto a la relación de medio a fin entre recibir reclamos y fiscalizar no es extensible a la promoción del entendimiento voluntario entre proveedor y consumidor, cuya finalidad es primariamente compensatoria y solo secundariamente dar cumplimiento a la regulación del consumo. Por su parte, la comunicación del reclamo para incentivar el arreglo individual es inherente a la función de dar protección a los derechos de los consumidores, como en primer lugar se ha destacado, en este caso, a través de la defensa de su derecho a la reparación e indemnización adecuada y oportuna.

${ }^{85}$ Artículo 58 inciso $2^{\circ}$ letra d), Ley $N^{\circ}$ 19.496, 1997.

${ }^{86}$ Artículo 58 inciso $2^{\circ}$ letra j), Ley $\mathrm{N}^{\circ}$ 19.496, 1997.

${ }^{87}$ Artículo 58 inciso $2^{\circ}$ letra k), Ley $\mathrm{N}^{\circ} 19.496,1997$.

${ }^{88}$ Artículo 58 inciso $2^{\circ}$ letra m), Ley $\mathrm{N}^{\circ} 19.496,1997$.

${ }^{89}$ Artículo 58 inciso $4^{\circ}$ y ss., Ley No $19.496,1997$.
} 
consecuencias no pueden considerarse atribuidas como poderes inherentes del SERNAC, puesto que la primera depende de la voluntad de las partes, de conformidad con lo dispuesto por los artículos 2.446 y siguientes del Código Civil, y la segunda, al tratarse de una privación, al consumidor y al servicio, del derecho a accionar ante un juez, es una materia reservada a la ley común. ${ }^{90}$

En virtud de lo señalado, el instrumento en que conste el acuerdo debe ser una transacción, una de cuyas cláusulas ha de contener la renuncia a la acción infraccional por parte del consumidor, sin que exista al efecto una dificultad, puesto que, como la LPDC lo dispone en su artículo $4^{\circ}$, la renuncia a los derechos que ese cuerpo normativo establece sólo está prohibida por anticipado, lo cual incluye la denuncia ante los tribunales. ${ }^{91}$ Ciertamente, lo anterior no significa la extinción de la acción infraccional para el SERNAC, ${ }^{92}$ aun cuando bastaría que la política del servicio para efectuar las denuncias ante los juzgados correspondientes contuviera precisamente la instrucción de que, habiendo entendimiento voluntario entre las partes, aquella no se ejerce, produciendo así un incentivo para que el proveedor presente una solución frente al reclamo del consumidor. La irrenunciabilidad de la acción por parte del servicio es, asimismo, una garantía para el acuerdo, cuyo incumplimiento por el proveedor debería ser fundamento suficiente para que, en la misma política de litigación de infracciones, se indique que tales casos deben necesariamente denunciarse. ${ }^{93}$

${ }^{90}$ En el sentido señalado en Tribunal Constitucional, 31 de marzo de 1998, Rol № 271, considerando $15^{\circ}$.

${ }^{91}$ Siguiendo aquí a Espada, Susana, "Artículo 40", en: De la Maza; Pizarro; Barrientos, cit. (n. 8), p. 195 , quien explica que los derechos cuya renunciabilidad procede, bajo las condiciones del artículo $4^{\circ}$ de la LPDC, son todos los poderes jurídicos que se otorgan al consumidor, calificables como derechos subjetivos.

92 Como lo explica Momberg, Rodrigo, “Artículo 4", en: De la Maza; Pizarro; Barrientos, cit. (n. 8), pp. 191-192, con jurisprudencia de referencia.

${ }^{93}$ La posibilidad de que el servicio establezca una política de litigación obedece a que la interposición de denuncias por parte del SERNAC es una materia discrecional, que depende de la evaluación que la agencia efectúe. Esto ha sido sostenido por la CGR en Contraloría General de la República, dictamen $\mathrm{N}^{\circ}$ 50.183, 7 de noviembre de 2007, según el cual: "el Servicio Nacional del Consumidor, en virtud de lo preceptuado en la letra g) del artículo 58 de la Ley $\mathrm{N}^{\mathrm{o}}$ 19.496, está dotado de atribuciones para denunciar los posibles incumplimientos de las normas que protegen a los consumidores ante los organismos o instancias jurisdiccionales respectivas y de hacerse parte en las causas que estén afectando los intereses de los consumidores, según los procedimientos que fijan las normas generales o los que se señalen en leyes especiales, de lo cual se desprende que el SERNAC tiene la facultad discrecional, entendida ésta como la voluntad de elección de la administración, dentro del marco legal y en su ámbito de competencia, de llevar a cabo tales actuaciones cuando la situación lo amerite." Véase la referencia en IsLER, cit. (n. 8), p. 1145. 
5. Implementación mediante la facultad interpretativa del Director Nacional del SERNAC

Para terminar, ha de señalarse que la implementación administrativa de la recepción de reclamos, comunicación al proveedor y promoción del entendimiento voluntario entre este y el consumidor debe efectuarse a través de la facultad interpretativa del SERNAC, con arreglo a lo dispuesto por el artículo 58 inciso $2^{\circ}$ letra b) de la LPDC. Esta potestad que, según el artículo 59 de la misma, se ejerce a través del Director del servicio, puede recaer en un amplio objeto susceptible de interpretación administrativa, a saber, "la normativa de protección de los derechos de los consumidores que le corresponde vigilar" al servicio, dentro de la que se incluyen, ciertamente, las funciones y atribuciones en este texto revisadas, en especial, aquellas referidas a velar por el cumplimiento de la LPDC, respecto a las cuales son inherentes la recepción de reclamos, comunicarlos al proveedor y promover un entendimiento entre las partes de la relación de consumo. Si bien, dichas interpretaciones son obligatorias solo para los funcionarios del SERNAC, eso no significa que no puedan tener efecto en terceros ${ }^{94}$ que voluntariamente deciden requerir al servicio y conseguir un arreglo.

\section{SUMA DE CONCLUSIONES}

El SERNAC puede implementar administrativamente la recepción de reclamos de consumidores, comunicarlos al proveedor y promover un entendimiento entre ambas partes en el ámbito individual, puesto que:

(i) No existe obstáculo constitucional para que el SERNAC pueda recibir reclamos, comunicarlos al proveedor y promover un acuerdo entre este y el consumidor en materias individuales, puesto que, según la jurisprudencia del mismo TC, estas no son materias jurisdiccionales. En concordancia con esto, lo que el TC declaró inconstitucional — esta vez por ser una materia jurisdiccional - fue la denuncia (que formaba parte del procedimiento administrativo sancionatorio del proyecto de fortalecimiento), mediación y conciliación obligatorias. Solo en estas condiciones hay inconstitucionalidad, cuestión que no se extiende a un mecanismo voluntario de recepción de

\footnotetext{
94 Técnicamente, se trata de "circulares normativas externas", según lo descrito en CorDERO, Eduardo, "Las normas administrativas y el sistema de fuentes", Revista de Derecho (Coquimbo), 2010, Vol. 17, $\mathrm{N}^{\mathrm{o}} 1$, p. 35 .
} 
reclamos, traslado al proveedor y promoción de acuerdos.

(ii) Por parte de los consumidores, la presentación de reclamos y la solicitud de que el servicio se dirija al proveedor para solucionar su problema, constituyen modalidades de ejercicio del derecho constitucional de petición ante la Administración, que se encuentra obligada a resolver el fondo de lo pedido en la medida que se halla dentro de la competencia del SERNAC la protección de los derechos de los consumidores.

(iii) La implementación administrativa de una modalidad de recepción de reclamos de los consumidores, comunicarlos al proveedor y promoción de un entendimiento individual es una potestad implícita respecto a otras que el SERNAC detenta expresamente, de manera que existe cobertura legal al efecto. En este punto, es especialmente relevante la información que a través de los reclamos se obtiene para fines de fiscalización cuyo objetivo final es hacer cumplir la regulación en materia del consumo.

(iv) Lo anterior es coherente con la manera en que se han entendido las potestades del SERNAC, en el sentido de que, a pesar de que algunas de ellas no se hallan explícitamente fijadas en las normas que lo rigen, igualmente, se ha admitido su ejercicio, según la interpretación finalista con la que se evalúa el ámbito de atribuciones del servicio, particularmente, respecto a lo dispuesto en el artículo 58 de la LPDC, referido a la función de velar por la legislación y los derechos de los consumidores.

\section{BIBLIOGRAFÍA CITADA}

\section{A) Doctrina}

Aguerrea, Pedro, "El Derecho de petición ante la Administración del Estado: acerca de la obligación de respuesta", Ius Publicum, 2002, № 9.

Aimone, Enrique, Derecho de protección al consumidor, Editorial Jurídica Conosur, Santiago, 1998.

BALDwIn, Robert; BLACK, Julia, "Really Responsive Regulation”, LSE Law Society Economy Working Papers, 2007, No 15.

Baldwin, Robert; Cave, Martin; Lodge, Martin, Understanding Regulation. Theory, Strategy and Practice, Oxford University Press, Oxford, 2012, 2 a edición.

Barrientos, Francisca; Fuentes, Claudio; Vargas, Juan Enrique, “"Mediaciones individuales' y 'mediaciones colectivas' que realiza el Servicio Nacional del Consumidor”, en: VÁsQuez, María F. (dir.), Mecanismos alternativos de solución de conflictos. Estado actual, problemas existentes y propuesta de 
soluciones, Thomson Reuters, Santiago, 2018.

Barrientos, Francisca; Soto, Pablo, "La teleserie legislativa sobre el texto de la ley de reforma del SERNAC: algunas propuestas", en línea: https:/www. elmostrador.cl/noticias/opinion/2018/04/02/la-teleserie-legislativa-sobre-el-textode-la-ley-de-reforma-del-sernac-algunas-propuestas/, 3 de diciembre de 2018.

Black, Julia, "Critical Reflections on Regulation”, Australian Journal of Legal Philosophy, 2002, No 27.

Bujosa, Lorenzo; Palomo, Diego, "Mediación electrónica: Perspectiva europea", Ius et Praxis, 2017, Año 23, No 2.

Cordero Quincazara, Eduardo, "Las normas administrativas y el sistema de fuentes", Revista de Derecho (Coquimbo), 2010, Vol. 17, № 1.

Cordero Vega, Luis, "La jurisprudencia administrativa en perspectiva: entre legislador positivo y juez activista. Comentario desde el dictamen sobre la píldora del día después", en: Couso, Javier (ed.), Anuario de Derecho público, Universidad Diego Portales, Santiago, 2010.

Cordero Vega, Luis, Lecciones de Derecho administrativo, Thomson Reuters, Santiago, 2015, $2^{\text {a }}$ edición corregida.

Duguit, Léon, Law in the Modern State, George Allen \& Unwin Ltd., Londres, 1921.

Espada, Susana, "Artículo 40", en: De la Maza, Í.; Pizarro, C. (dirs.); BARrientos, Francisca (coord.), La protección de los derechos de los consumidores. Comentarios a la Ley de protección a los derechos de los consumidores, Legal Publishing-Thomson Reuters, Santiago, 2013.

García de Enterría, Eduardo; Fernández, Tomás-Ramón, Curso de Derecho administrativo, Civitas-Thomson Reuters, Navarra, 2011, 15 a edición, tomo I.

Guiloff, Matías, "Operativizando la relación ley-reglamento: una propuesta de redefinición del rol de la reserva legal", Revista de Derecho (Valdivia), 2012, Vol. XXV, $\mathrm{N}^{\mathrm{o}} 1$.

Hawkins, Keith; Thomas, John, "The Enforcement Process in Regulatory Bureaucracies", en: Hawkins, Keith; Thomas, John (eds.), Enforcing Regulation, Kluwer-Nijhoff Publishing, Boston, 1984.

Isler, Erika, “Artículo 58”, en: De la Maza, Íñigo y Pizarro, Carlos (dirs.); BARrientos, Francisca (coord.), La protección de los derechos de los consumidores. Comentarios a la Ley de protección a los derechos de los consumidores, Legal Publishing-Thomson Reuters, Santiago, 2013.

IsLeR, Erika, "La facultad del Servicio Nacional del Consumidor para denunciar infracciones a la Ley N 19.496 (Corte de Apelaciones de Santiago)", Revista de Derecho (Valdivia), 2014, Vol. XXVII, No 1.

Momberg, Rodrigo, "Artículo 4", en: De la Maza, Íñigo y Pizarro, Carlos (dirs.); BARrientos, Francisca (coord.), La protección de los derechos de los consumidores. Comentarios a la Ley de protección a los derechos de los 
consumidores, Legal Publishing-Thomson Reuters, Santiago, 2013.

NogueIRA, Humberto, "El derecho constitucional de petición y su insuficiente regulación legislativa", Revista de Derecho (Coquimbo), 2008, vol. 15, Nº 2.

OelcKers, Osvaldo, "El principio de legalidad como supuesto de la potestad administrativa", Revista de derecho Pontificia Universidad Católica de Valparaíso, $1977, \mathrm{~N}^{0} 1$.

Santamaría, Juan, Principios de Derecho administrativo general, Iustel, Madrid, 2004, tomo I.

Servicio Nacional del Consumidor, "Reporte estadísticos de reclamos", en línea: https://www.sernac.cl/portal/619/articles-4093_archivo_01.pdf, 2 de diciembre de 2018.

Servicio Nacional del Consumidor, "Ranking de Reclamos Telecomunicaciones”, en línea: https://www.sernac.cl/portal/619/articles-54978_ archivo_01.pdf, 2 de diciembre de 2018.

Sото, Pablo, "El giro conservador en torno a las sanciones administrativas por obra del Tribunal Constitucional en Chile: transformando a la Administración en juez para desproteger el interés público", Revista de la Facultad de Derecho Universidad de la República (Uruguay), 2018, Nº 45.

Stiglitz, Joseph, "Government Failure vs. Market Failure: Principles of Regulation", en: BALleisen, Edward; Moss, David (eds.), Government and Markets: Toward a New Theory of Regulation, Cambridge University Press, New York, 2009.

Veljanowski, Cento, "Strategic Use of Regulation", en: Baldwin, Robert; Cave, Martin; Lodge, Martin (eds.), The Oxford Handbook of Regulation, Oxford University Press, Oxford, 2013.

\section{B) Jurisprudencia citada}

Contraloría General de la República, dictamen $\mathrm{N}^{\circ} 23.314,14$ de noviembre de 2018.

Contraloría General de la República, dictamen $N^{\circ} 59.778,21$ de noviembre de 2011. 2010 .

Contraloría General de la República, dictamen $\mathrm{N}^{\circ} 21.480,23$ de abril de

Contraloría General de la República, dictamen $N^{0} 84.724,23$ de noviembre de 2016.

Contraloría General de la República, dictamen $N^{\circ} 19.343,25$ de abril de 2005. 2000

Contraloría General de la República, dictamen $N^{\circ}$ 23.404, 26 de junio de

Contraloría General de la República, dictamen $\mathrm{N}^{\circ} 24.828,3$ de octubre de 
2018.

Contraloría General de la República, dictamen $N^{\circ} 68.467,31$ de octubre de 2012.

Contraloría General de la República, dictamen $N^{\circ}$ 94.206, 4 de diciembre de 2014.

Contraloría General de la República, dictamen $\mathrm{N}^{\circ} 72.369,4$ de octubre de 2016.

Contraloría General de la República, dictamen $\mathrm{N}^{\circ}$ 50.183, 7 de noviembre de 2007.

Contraloría General de la República, dictamen N 43.644, 9 de julio de 2013.

Contraloría General de la República, dictamen $\mathrm{N}^{\circ} 47.272,9$ de octubre de 2002.

Corte de Apelaciones de Santiago, 10 de julio de 2013, Rol No 1715-2012.

Tribunal Constitucional, 18 de enero de 2018, Rol No 4012-17.

Tribunal Constitucional, 27 de enero de 1997, Rol No 251.

Tribunal Constitucional, 27 de junio de 2004, Rol No 411.

Tribunal Constitucional, 31 de marzo de 1998, Rol No 271.

\section{C) Fuentes legales}

D.F.L. $\mathrm{N}^{\circ} 1 / 19.653,2001$.

D.F.L. $\mathrm{N}^{\circ} 2,1967$.

Ley $\mathrm{N}^{\circ} 18.045,1981$.

Ley $\mathrm{N}^{\circ} 18.575,1986$.

Ley $\mathrm{N}^{\circ} 19.880,2003$

Ley No 20.417, 2010.

Ley No 19.496, 1997.

Ley $N^{0}$ 19.955, 2004.

Ley $\mathrm{N}^{\mathrm{o}} 21.081,2018$. 